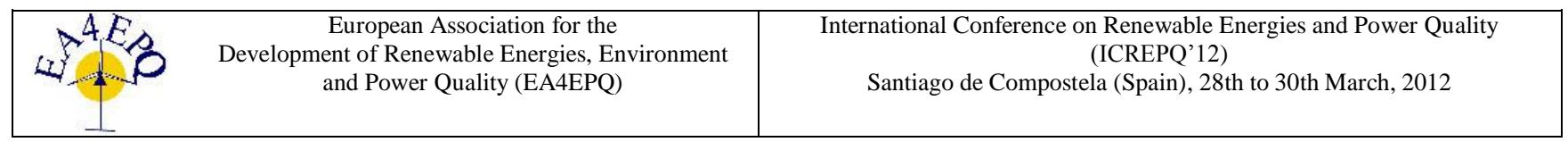

\title{
Design and analysis of a Hybrid Drying Using Renewable Technologies Emérita Delgado ${ }^{1,2 *}$, Juan Peralta ${ }^{1}$, Ivan Arboleda ${ }^{1}$, A. López Agüera ${ }^{2}$
}

\author{
1,- Center of Technology Development Sustentable \\ Mechanical Engineering, Escuela Superior Politécnica del Litoral (ESPOL) \\ Km 30.5 vía perimetral, Ecuador
}

Phone/Fax number 0059304 2269359, email: eadelgad@espol.edu.ec,jperalta@espol.edu.ec,abarriga@espol.edu.ec

2 Sustentable Energetic Applications Group. Astroparticle Group.

Physics Faculty, Santiago of Compostela University

Rúa Xosé María Suárez Núñez. s/n 15782. Santiago of Compostela (Spain)

Phone/Fax number: 0034981563100 ext. 14000, email: a.lopez.aguera@usc.es

\begin{abstract}
The design and construction of a hybrid prototype for drying algal biomass is presented. The dryer is composed from a solar induced air collector and a greenhouse drying chamber which main energy source is that one coming from the sun. It is complemented with an electric system used as auxiliary heating mechanism.
\end{abstract}

During the data collection, meteorological conditions (radiation, temperature, local humidity) were measured in order to determine the effect on the final quality of biomass going to be used.

The drying productivity is analyzed in function of the solar energy received and the product moisture. The drying rate curves of the selected samples, finally, curves of behavior variation of the temperature profile were elaborated;. Useful energy, theoretical and experimental losses of the system were obtained and during the development of the project

Key words : Dryer, biomass, solar energy, collector.

\section{Introduction}

At the present time there is a political interest of the Ecuadorian government in the production, commercialization and use of biofuels. One of the alternatives from the energetic viewpoint is the production of biofuel using algal biomass as raw material because of its high productivity index and the possibility that the product could generate less atmospheric pollution compared to fossil fuels.

On the other hand, one of the disadvantages of using this kind of biomass is its high processing cost mostly at the drying stage, because of the energetic requirement of the process when conventional energy sources are involved.
Pharmaceutical companies and food industries that meet the standards of product quality control use during the dehydration process, conventional drying equipment that consumes large quantities of energy. Among conventional dryers are: trays or tray dryer, tunnel dryer, rotary dryer, spray dryer. It should be noted that in the field of biofuel extraction methods using centrifugation and lyophilized.

This work is focused on the application of solar thermal systems as an alternative drying mechanism, based on the global concern which nowadays forces the development of projects that let the using of alternative energies in the biomass process, achieving the reduction of the final product cost.

The general objective is to contribute with the national technological development of biomass drying system using renewable "solar" energy sources, as well as improve the characteristics of the final product compared to conventional models.

\section{Methodology}

First stage: Consist in the collection and further analysis of different species of regional algaes. (Region of Ballenita located on the coast of the province of Santa Elena in Ecuador). During the analysis of the samples physical -chemical parameters were determined. (moisture content, percentage of lipids, and others).

The Algae species studied were: green macroalgae (codium) and brown macroalgae (Padina and sargassum). 


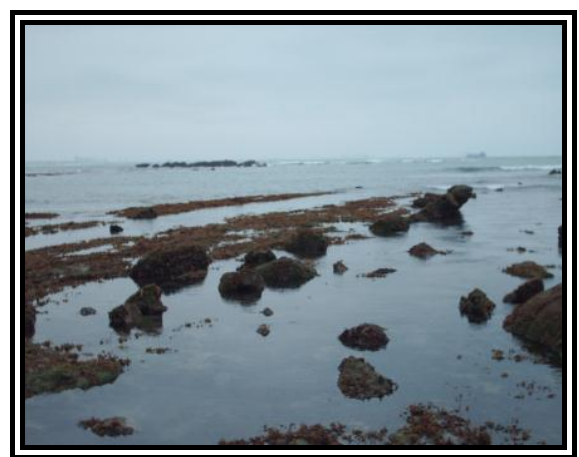

Fig 1. Ballenita coast (Ecuador): View of algal species

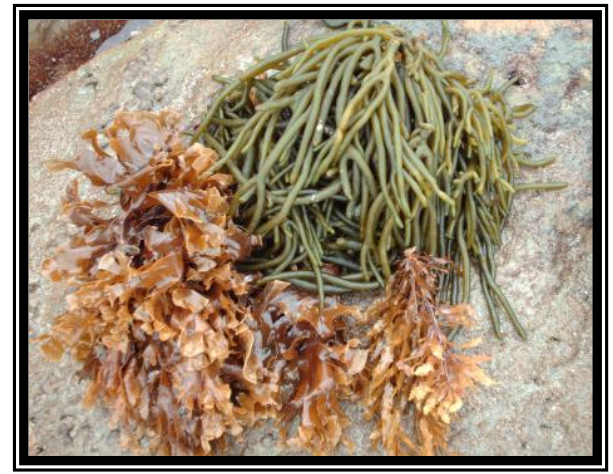

Fig 2. Algal species: Sargassum, Padina and Codium

Table I. Moisture content of the selected samples.

\begin{tabular}{|l|c|l|}
\hline Samples & $\begin{array}{l}\text { \% Humidity ( wet } \\
\text { base) }\end{array}$ & Method \\
\hline Sargassum & 85.09 & Gravimetric \\
\hline Padina & 22.36 & Termobalance \\
\hline Codium & 13.7 & Termobalance \\
\hline
\end{tabular}

Table2. Percentage of lipids *

\begin{tabular}{|l|c|}
\hline Samples & \% porcentaje of lipids \\
\hline Sargassum & 85.09 \\
\hline Padina & 22.36 \\
\hline Codium & 13.7 \\
\hline
\end{tabular}

* The method used of this test was soxhlet be one of the official AOAC methods 14.059. (1960).

Second stage: The curves of drying speed for the selected samples through a conventional dehydrator were determined experimentally The following factors: temperature, cutting uniformity in the size of the samples, air velocity were controlled [1]. In addition, we obtained desorption isotherms to calculate the final moisture content of the sample

Moisture content on dry basic ;

$$
X_{t}=\frac{W-\mathrm{W}_{\mathrm{S}}}{\mathrm{W}_{\mathrm{S}}}
$$

Free moisture content in the sample;

$$
X=X_{t}-X^{*}
$$

Drying speed

$$
R=-\frac{W_{S}}{A}\left(\frac{\partial X}{\partial t}\right)
$$

Furthermore, the characteristic drying curve is presented. It was obtained by using the traditional drying method and the desorption isothermal curve of Padina and Codium samples.

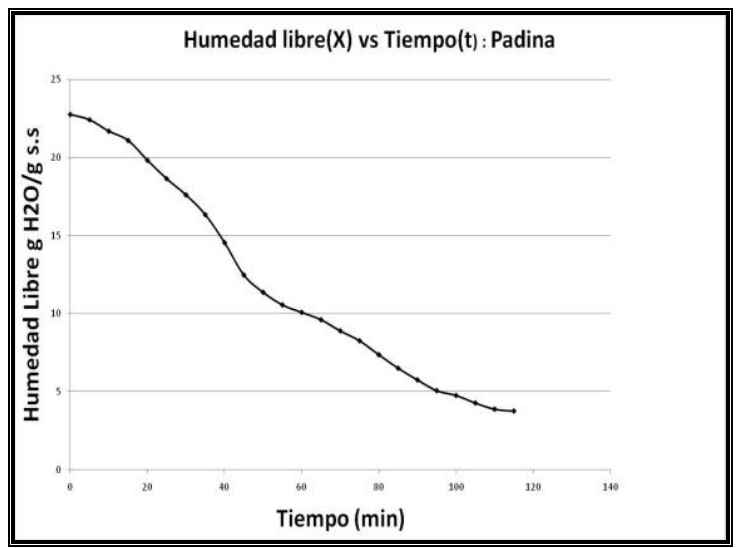

Fig 3. Drying curve Codium sample obtained by traditional drying method

As observed in Fig. 3, during the first minutes the free humidity of the product is significant due to the fact that the alga quickly lose water from the surface. After that, the absorption starts to get slower because the cytoplasm starts to be gel-like, that is to say that it becomes denser due to the water loss.

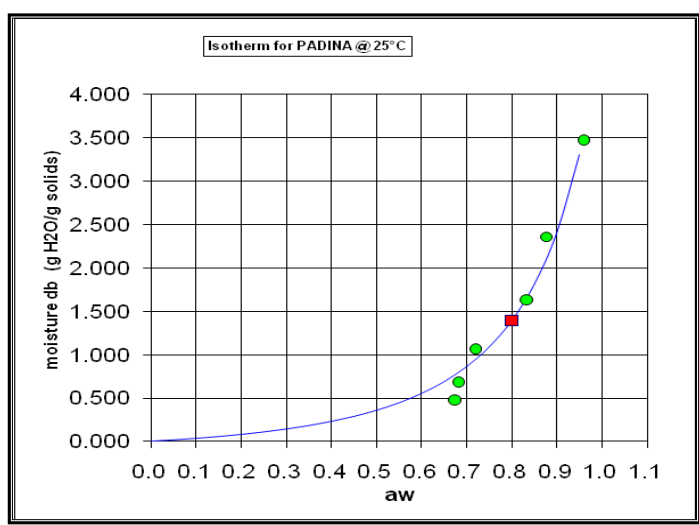

Fig 4. Desorption Isotherm of Codium sample, at 25 C, 1 Atm de pressure .

The isotherms show a characteristic of type III products with anti-caking agents.

This type of species water adsorbed at specific sites, the union has very strong links, which lowers the water activity drastically. [5].

Third stage : the low temperature thermosolar prototype was designed and dimensioned on the basis of the data of the region weather conditions like solar irradiation, wind speed, relative humidity and geographic situation. 


\section{Design of the hybrid system.}

The prototype is formed by an induced draft plane collector which will follow the same principle of greenhouse effect, and a dehydration chamber made of a low reflectance material that allows the solar radiation passing to heat the volume of air inside. Because of the variation of daily radiation that origins a fluctuation of heat, an auxiliary system consisting of an electric resistance in the chamber .

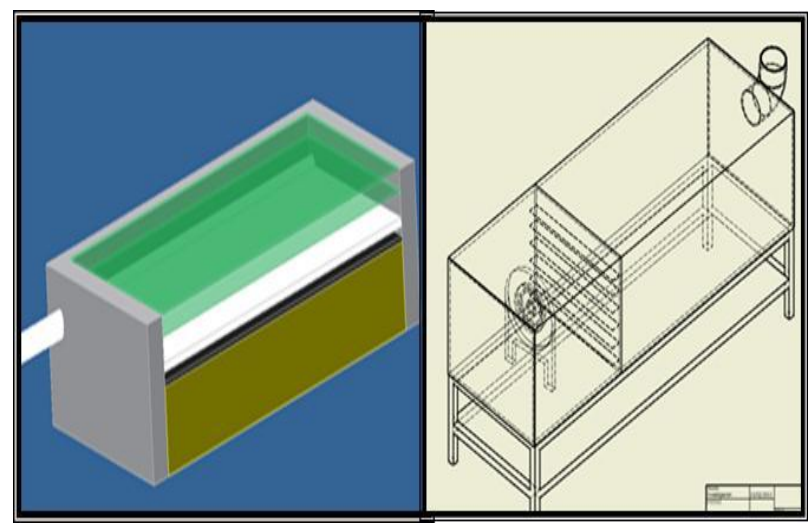

Fig. 5. Prototype hybrid dryer.

The energy balance of the collector was made to the area, gain factor, solar radiation absorbed per unit area of the plate, global loss coefficient and difference of temperatures between the environment and the collector's inlet; in order to make the sizing and the mathematical analysis of itself, finally orientation and the optimum angle of the collector inclination were determined.

$$
Q_{u}=A_{c} \cdot F_{R} \cdot\left[S-U_{L} \cdot\left(T_{f e}-T_{a}\right)\right]
$$

In order to determine the orientation and optimum tilt angle of the solar collector $(\beta)$, it is necessary to know the direct solar irradiation and the average diffuse as well as the ground albedo.

$$
\mathrm{G}_{\mathrm{T}}=\mathrm{G}_{\mathrm{b}} \mathrm{R}_{\mathrm{b}}+\mathrm{G}_{\mathrm{dT}}
$$

The best tilt angle $(\beta)$ turns out to be $15^{\circ}$ for a latitude ( $\lambda$ ) $2^{\circ} 08^{\prime} 45.99000^{\prime \prime}$ South and longitude $79^{\circ} 57^{\prime}$ 51.09690 "West.

Based on the location data, solar declination is determined during the 365 days a year; hour angle at solar noon, solar zenith angle, solar elevation and azimuth angle.

For the sizing of the drying chamber a balance of mass and energy was carried out, taking the exchange between the warm air flow, the product within the trays and the internal walls of the dryer .( Eq. 6)

$$
\begin{aligned}
m_{a, c} * C_{p a} \cdot\left(T_{e, a}\right. & \left.-T_{s, a}\right) \\
& =h_{, b 1} \cdot A_{b}\left(T_{e, a}-T_{p 1}\right) \\
& +h_{b 2} \cdot A_{b}\left(T_{e, a, m e d}\right. \\
& \left.-T_{p 2}\right)+h_{, b 3} \cdot A_{b}\left(T_{e, a, m e d}-T_{p 3}\right) \\
& +h_{a, p a r e d} \cdot A_{\text {pared }} \cdot\left(T_{e, a}-T_{\text {pared }}\right)
\end{aligned}
$$

Ec. 6

Since the heat air supplies energy to the product, one part is stored and another is used to evaporate humidity, so a mass balance between the humid product, the necessary amount of energy to dehydrate, the dry mass and the latent heat of evaporation is used. [7]

$$
\begin{aligned}
& m_{\text {prod.humedo }} \cdot C_{p, \text { prod }}\left(\frac{d \text { Tpord }}{d t}\right)= \\
& h_{\text {prod ,hum }} A_{b}\left(T_{a, e}-T_{p}\right)-m_{\text {pro.seco }} L_{v}(\mathrm{DM} / \mathrm{dt})
\end{aligned}
$$

Ec 7

\section{Performance testing.}

During the system valorization multiple field tests were made to evaluate the functioning and behavior of the experimental prototype (collector and drying chamber), monitoring the main variables or parameters that have influence in the drying process; like the following:

- Collector: inlet and inlet temperature of heat transfer fluid.

- Chamber: indoor humidity, indoor temperature and the product.

- Variation of mass of the sample along the drying period.

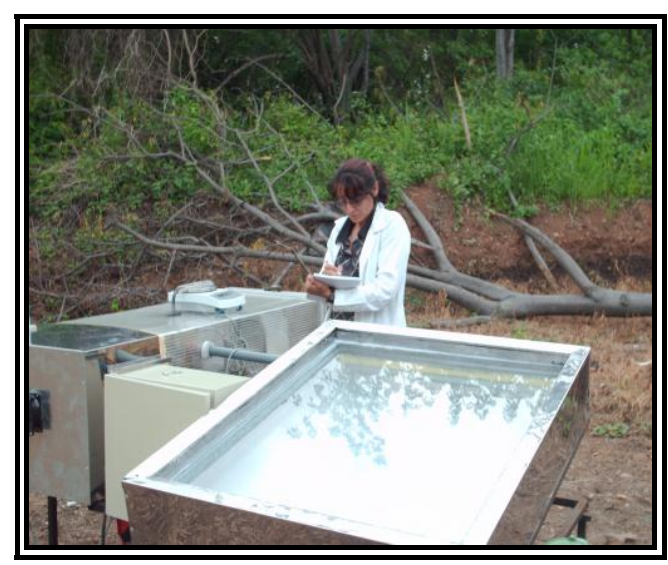

Fig 6. Register experimental data

The result of this investigation we describe like this;

1) Variation of temperatures in the collector and chamber with respect to time and the fluctuation of solar radiation.

Below, the air flow temperature values at the collector's input and output are plotted and the air 
warming over time due to the incoming irradiation which gets trapped is observed.

During the stage, a noticeable temperature increase of 40 degrees was determined at the air flow output with respect to the environmental temperature for global irradiations higher than $400 \mathrm{~W} / \mathrm{m}^{2}$.

For cloudy days and irradiations lower than $300 \mathrm{~W} / \mathrm{m} 2$, the fluid which carries the heat increases the temperature between 10 and 15 degrees.

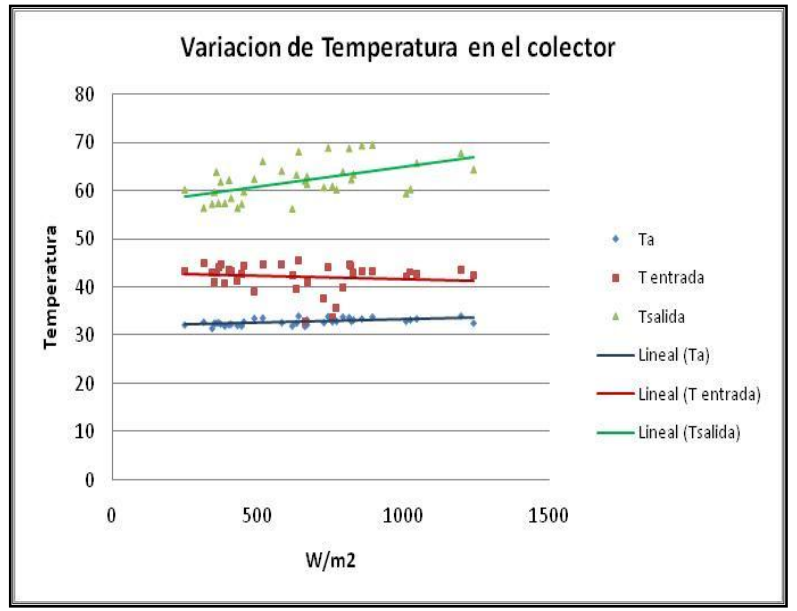

Fig 7. Data logging of temperature in the collector

The drying chamber got temperatures higher than 70 degrees when the irradiation was higher than $450 \mathrm{~W} / \mathrm{m} 2$; when the irradiation is lower, the temperature is comprised between 30 and $60^{\circ} \mathrm{C}$.

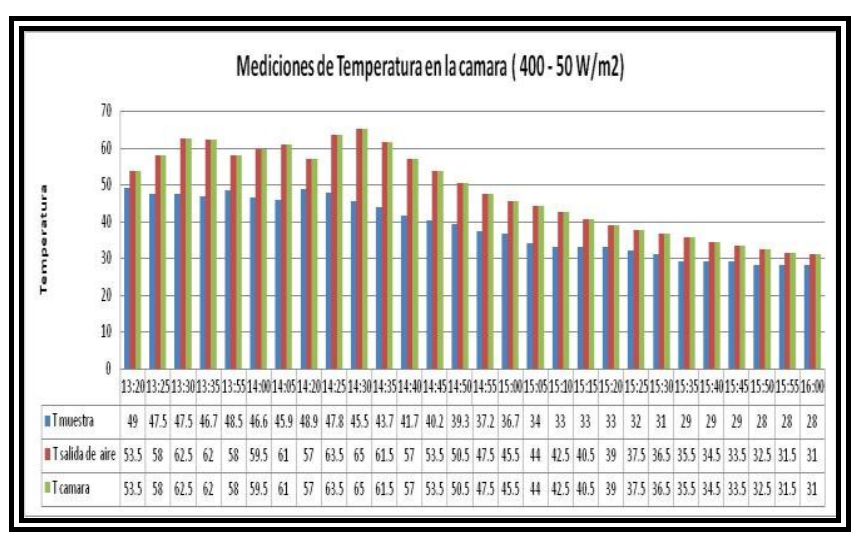

Fig. 8. Data logging of temperature in the drying chamber

2) Efficiency of each component and the system with respect to radiation.

The collector efficiency varies during the day, depending on the solar irradiation that arrives at the surface of the equipment, and the climate conditions of the area. In Fig, 9, a comparison between two months of the year could be observed, establishing a collector efficiency within the range of $14-29 \%$.

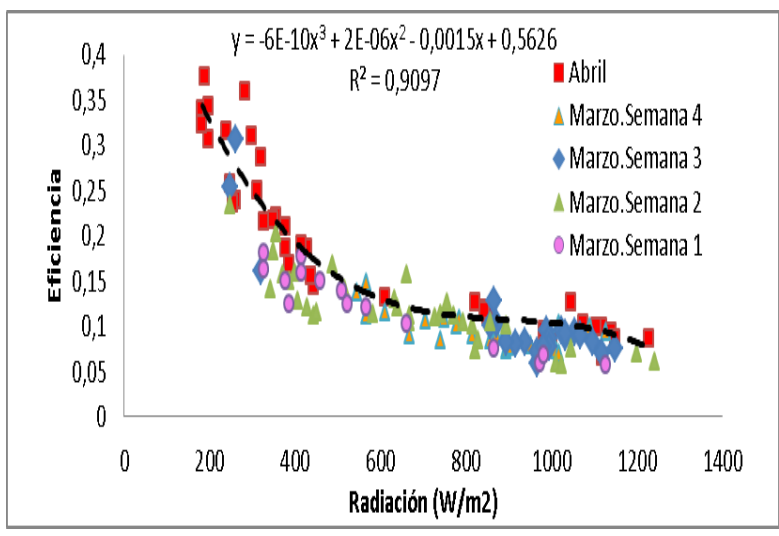

Fig 9 .Experimental parameters between efficiency and solar radiation to the collector (March and April)

3) Mass loss of biomass samples with respect to time.

During the experimental phase of the equipment, a dehydration of the three kind of algae biomass (Sargassum, Padina and codium) was carried out with the aim of obtaining the average drying curve of the product, by using the solar prototype, and carrying out the comparison with the drying curves that were obtained by means of the traditional drying.

In Fig, 10's plots, the results obtained in the experimental test (solar system) are presented. They fit the curve shape for the biomass sample that was showed in Fig.3.

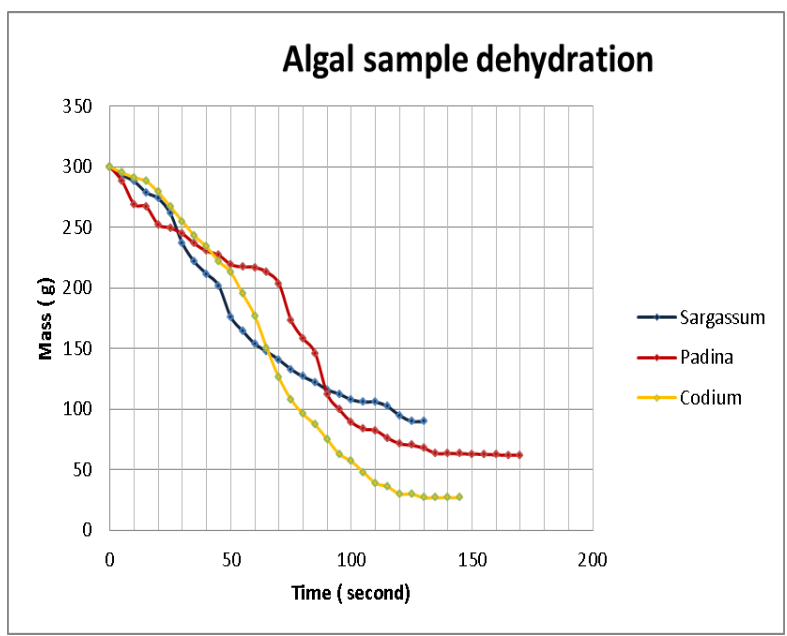

Fig 9. Moisture loss simple over a period of time in the range of average radiation $\left(500\right.$ a $\left.200 \mathrm{~W} / \mathrm{m}^{2}\right)$

4) The energy supply by solar radiation input and contribution of the hybrid system.

As the equipment depends on the climate conditions of the place, it was necessary to install a support system that was composed of an electric resistor (it uses electric energy) which is controlled by means of automatic system that is turned on when a thermocouple which is placed in the chamber registers temperatures lower than 70 degrees. In order to cover the electric demand, a $100 \mathrm{Wp}$ solar module and a 155 Ah battery for accumulation could be used. 
5) Finally, we performed comparison of adsorption isotherms obtained by conventional drying and solar drying.

\section{Conclusion}

It is designed and built a prototype dryer using solar energy as the main source. Costa of two parts: a solar collector with an experimental efficiency of 14 to $27 \%$. And a drying chamber with an efficiency of $80 \%$.

The experimental tests were subjected to different environmental parameters such as: wind, rain, cloudiness of the place.

Conclude, at intensities greater than $400 \mathrm{~W} / \mathrm{m} 2(96 \mathrm{~W})$ were recorded inside the chamber temperature between 77 C. At lower irradiation temperature was obtained under $52 \mathrm{C}$.

Moreover, we reduce the operation cost by savings around $60 \%$ of electricity consumption. The quality of the final product is improved and the drying time was reduced.

\section{Gratitudes}

- Secretaria Nacional de Educación Superior Ciencia y Tecnología SENESCYT (Ecuador).

\section{References}

[1] Vásquez, Tania. Arnés, Silvia. Fernández, Miguel. Fernandez, Juan. . Technical Manual solar food drying. Energy, FACK, Recerca e Cooperazine . Cochabamba, Bolivia. 1997.

[2] Omaña, Mónica. Sorption isotherms of water in extractive residues orange juice. $\mathrm{Pp}$ 63. Pontificia Bolivariana University. Medellín, Colombia. 2010.

[3] Montero, irene Model and Construction of a hybrid solar dryer for biomass residues. Extremadura of University, School of Industrial Engineering. Badajoz, España. 2005.

[4] Various Authors. Solar stove wood drying. SEMARNAT, National Institute for Forestry, Agriculture and Livestock, National Forestry Commission. México. 2008.

[5] Castillo, María . Diseño del proceso de Obtención de trozos secos de Carambola tratados Osmóticamente. pp 33 . Escuela Superior Politécnica del Litoral, Ingeniería de Alimentos. Guayaquil, Ecuador. 2007

[6] Palomino, M. Estrada, F. López, G. Microalgas : potencia para la producción de biodiesel . Universidad del Valle. Cali, Colombia. 2010
[7] Domínguez, Ana. Evaluación del efecto de tres condiciones de almacenamiento sobre la estabilidad y tiempo de vida en anaquel de panela granulada, pp. 23. Escuela Politécnica Nacional. Quito, Ecuador. March 2009.

[8] Más, Javier. Energía Solar Térmica de baja media y alta temperatura. Cap. 4. Universidad de Santiago de Compostela. Santiago de Compostela - Spain. 16 de November del 2009.

[9] Gerardo. Alimentos. Universidad Mayor de San Marcos. Perú, November 1999.

[10] López, Miguel. Sánchez, Herman. Elaboración de Sopa Instantánea a partir de harina de frejol. Pp 35. Escuela Superior Politécnica del Litoral, Ingeniería de Alimentos. Guayaquil, Ecuador .2011 